\title{
OPINION AND ATTITUDES OF CHILDREN HIGHER GRADES OF PRIMARY SCHOOL ON ELECTRONIC SPORTS
}

\author{
Dusan Stankovic, Marko Kostadinovic
}

Summary: Electronic sport from day to day is becoming more popular and more interesting. Video games and gaming devices are designed to be as realistic as possible. Producers of video games want their games to be more interesting to players, to play in clans in order to connect more players, thereby is providing a difficulty in the game playing. The subject of research are opinions and attitudes of children on electronic sports, their basic knowledge and experience. The primary goal of the research is to create a realistic image of e-sports based on the conducted survey in order to objectively view further perspectives of the development of this sport. The tested subjects are middle school students. The total number of respondents is 100, of which makes up 50 girls and 50 boys. The results of the survey were processed by nonparametric statistics, using SPSS program. Besides the descriptive statistics and Chi-square test is shown, which were tested differences of expected and obtained frequency depending of gender. All research results are shown in graphs. General conclusion was that boys and girls have very difference opinions on e-sports, except for the future of ordinary and electronic sports.

Key Words: electronic sport, e-sport, nonparametric statistics, Chi-square test

\section{Introduction}

An electronic sport known as an e-sport or video game competition, is a fun sport based on individual or team video games which are played against each other in order to get money prize or become popular and famous (Heaven, 2014). Today there are huge discussions about whether e-sport is really a sport or just a competition like chess (Tassi, 2014). The term e-sport has existed for several decades (Hope, 2015). During the 1970s and 1980s, video games, players and tournaments have started to appear in popular websites and magazines. E-sport events were broadcast on television between 1982 and 1984. A total of 133 episodes were broadcast. During the 1990s, many games began to play online. Most of these games were games for the computer. In 1993, the "Wired" magazine opened the "first store sports game". Oxford defines e-sport as a computer game that is played in professional competition, especially when it is watched by fans and broadcasting over television or the Internet. Wagner (2006) defines e-sport as an area of sports activity in which people develop and train mental and physical abilities by using information and communication technologies. E-sport can be considered a "sport", by definition, in the same way as chess or poker. There are many parallels between traditional sports and e-sport. However, the virtual environment and the lack of physical activity are questioning whether we can really define e-sport as a regular sport or mental sport. A video game is an electronic game that involves interacting with a user interface to generate visual feedback on video devices such as a TV screen or monitor. Since the 2000s, the video game can be displayed on any type of device screen that can produce a two-dimensional or three-dimensional image. Some theorists categorize video games as an artistic form, but this label is controversial. The most famous global cyber game tournaments are the "Electronic Sports World Cup " which is happening in France. "World Cyber Games" which is happening all over the world and is otherwise called cyber sport Olympics. 'Electronic Sports World Cup" is the leading international sport event in the world of games. This tournament combines the best players in the world and their fans. It is happening 3 to 5 times a year. "World Cyber Games", this event is a traditional sports tournament that strives to be like the Olympic Games, which includes the official opening ceremony, and players from different countries are competing for gold, silver and bronze medals. The main goal of the research is to get a realistic picture of the phenomenon of electronic sport on the tested sample based on the conducted survey in order to objectively look at the further perspective development of this sport in our environment and to determine differences in responses in boys and girls. 


\section{Methods}

The sample of respondents are boys and girls of higher grades of primary school. The total number of respondents is $\mathrm{N}=100$. A measuring instrument in this research is a modified questionnaire composed of several questions. The obtained results of the survey were processed by nonparametric statistics using the SPSS program. In addition to descriptive statistics, a Chi-square test is also shown, which were tested the differences between the expected and the received frequencies for the response between boys and girls.

\section{Results and Discussion}

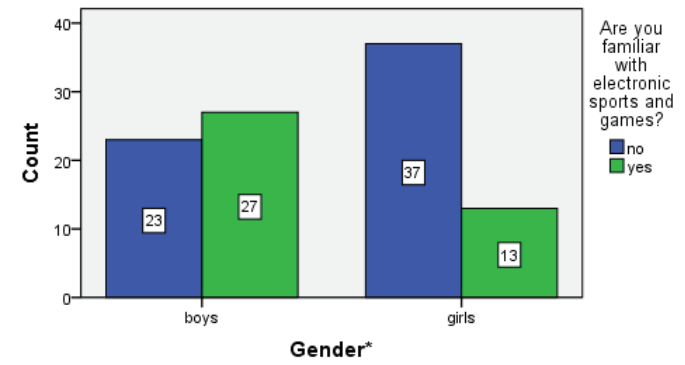

Figure 1 Are you familiar with electronic sports and games?

The first question was how many respondents are familiar to electronic sports and competitive games. Research has shown that $60 \%$ of respondents are not familiar to electronic sports while $40 \%$ are. The boys and girls are statistically significantly differ in answering this question.

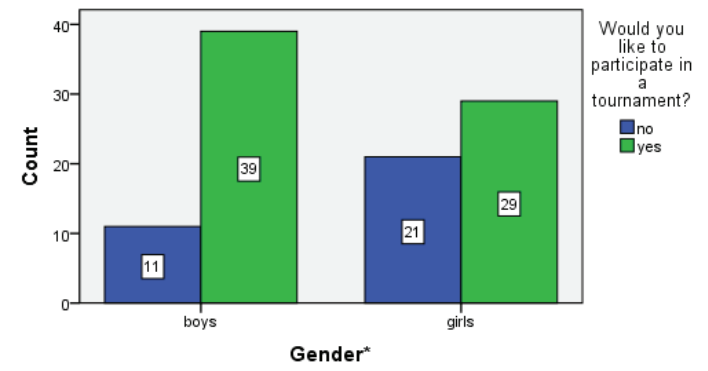

Figure 2 Would you like to participate in a tournament?

On question, "Would you like to participate in a tournament?", respondents had a positive answer, $68 \%$ of respondents said they would like to participate in some of the electronic sports tournaments, while $32 \%$ of respondents are not interested in e-sport tournaments. And here is statistically significant connection between gender and desire to participate in tournaments. There are many more boys who responded positively to this question.

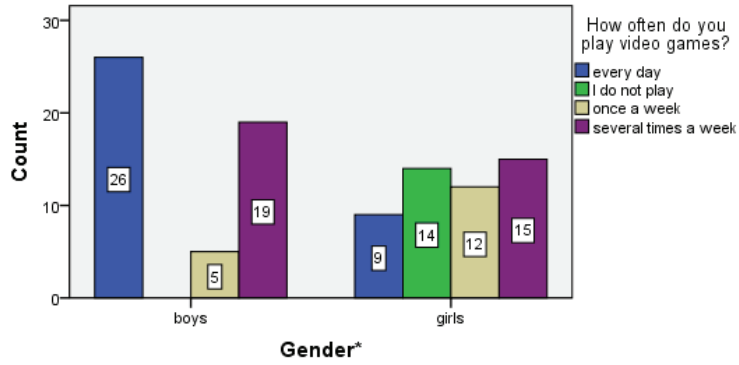

Figure 3 How often do you play video games?

On this graph we see that boys play more video games than girls, even 45 of them play every day or several times a week. No boy answered that he did not play the games, while 14 girls do not play. And here we have a significant difference in the answers between boys and girls.

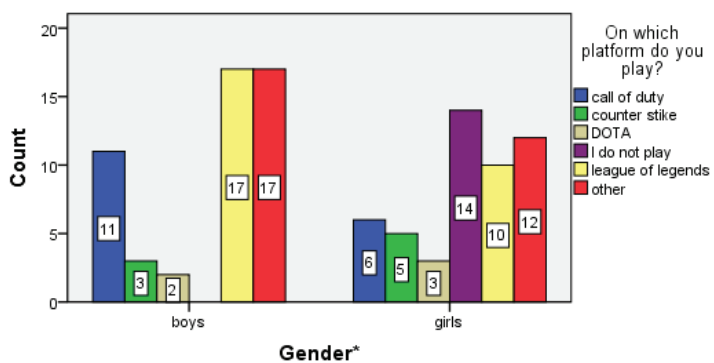

Figure 4 On which platform do you play?

On question "On which platform do you play", the answers were very diverse. Definitely, even in boys and girls, the League of Legends prevails, even $27 \%$ of respondents, representing almost $1 / 3$.

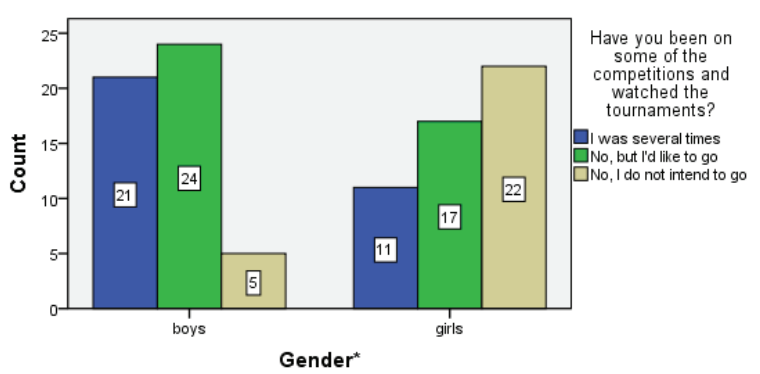

Figure 5 Have you been on some of the competitions and watched the tournaments?

The next question is shown in graph number 5 . We see that $90 \%$ of boys have been several times or would like to go and watch e-sport tournaments. In girls, this number is much smaller, even $44 \%$, almost half of respondents do not intend to go.

The answers of the respondents, as in the previous questions, statistically significantly depend on half of the respondents, namely they were different. 


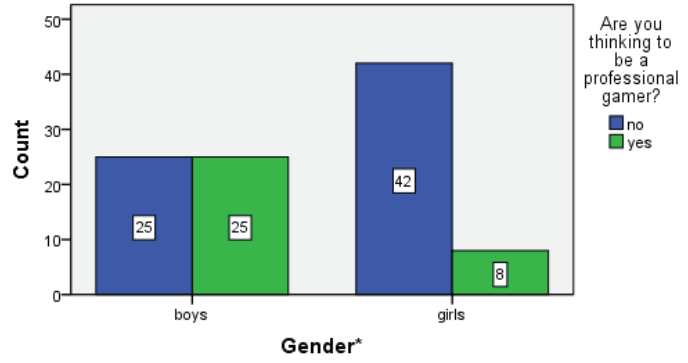

Figure 6 Are you thinking to be a professional gamer?

The graph above shows the results of the answer to the question "Are you thinking to be a professional gamer"? The responses of the boys are absolutely divided, while $84 \%$ of girls do not want to be. And here by analysis of the Chi-square test, the answers statistically significantly depend on gender.

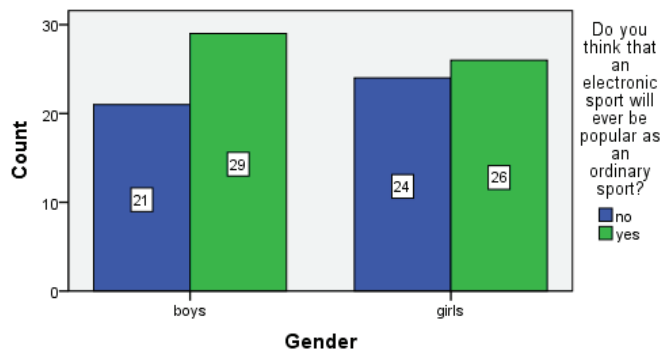

Figure 7 Do you think that an electronic sport will ever be popular as an ordinary sport?

On the last question, we received the only independence in the answers regarding gender. Namely, boys and girls in their answers also presented similar thoughts and attitudes. In a very approximate number, both genders consider that e-sport will never be popular as a classic sport.

\section{Conclusion}

With the development of Internet and gaming devices, video games are becoming more numerous, and electronic sport is becoming more serious and more popular. As the development of technology progresses, the games become more demanding and harder to play, thus players are getting better, regardless of whether they are amateur or professional gamers. Professionally dealing with this sport requires great disclaimers and constant renewal of new technology. It can be said that electronic sport is not cheap at all. Based on this research, it was concluded that playing games is much more popular and familiar to respondents than dealing with professional gaming. Research also showed the great desire of the respondents to play games and to learn about the basics of electronic sports. The result of the research has shown that boys play more games than girls, and that they have a greater desire to discover and deal with electronic sports. The answers to the questions are mostly statistically dependent on half of the respondents, except in the last question, so we can hope that the future of classic sport may not be endangered.

\section{References}

B92 esports. Preuzeto 18.04.2017, sa http://www.b92. net/esports/dota2.php?order=priority

Elektronski sport - video igrice kao nova sportska disciplina. Preuzeto 18.04.2017, sa http://internetzanatlija.com/2012/12/21/elektronski-sport-video-igrice-kao-nova-sportska-disciplina/

Esportovi popularniji od NBA finala. Preuzeto 18.04.2017, sa http://www.klanrur.rs/2016/09/11/esportovi-popularniji-od-nba-finala/

Heaven, D. (2014). Rise and Rise of Esports. New Scientist, 223 (2982), 17

Hope, A. (2014). The Evolution Of The Electronic Sports Entertainment Industry And Its Popularity. In Computers For Everyone [online] 1st edn. ed. by Sharp, J. and Self, R. 87-89.

Tassi, P (2014). ESPN Boss Declares eSports "Not a Sport" Forbes [Online] 9th July.

Wagner, M. (2006). On the Scientific Relevance of eSports. In International Conference on Internet Computing [online] held 2006. 437-442. 